1. Students are predominantly white males from middle-class families.

2. The main sources for these video clips were the $\mathrm{ABC}$ News interactive discs, Powers of the Congress, Powers of the President, and Powers of the Supreme Court; a preproduction video disc designed to accompany Ken Janda's American government text, The Challenge of Democracy, Houghton Mifflin Publisher; an American government disc marketed by Harper-Collins; and various VHS clips collected by members of the department over the years.

3. Statistically this creates a one-tail test for significance.

4. The fact that the students in the video sections performed no better on the nonvideo questions also suggests that there was no spillover effect or that the use of video would spur a generally higher performance on all questions.

5. In addition to two examinations and a final examination, there were two short papers.

\section{References}

Janda, Kenneth. 1992. "Multimedia in Political Science: Sobering Lessons from a Teaching Experiment." Journal of Educational Multimedia and Hypermedia $1: 341-54$.

Spencer, Ken. 1991. "Modes, Media, and Methods: The Search for Educational Effectiveness." British Journal of Educational Technology 22:12-22.

Summers, Jerry A. 1990-91. "Effect of Interactivity Upon Student Achievement, Completion Intervals, and Affective Perceptions." Journal of Educational Technology Systems 19:53-57.

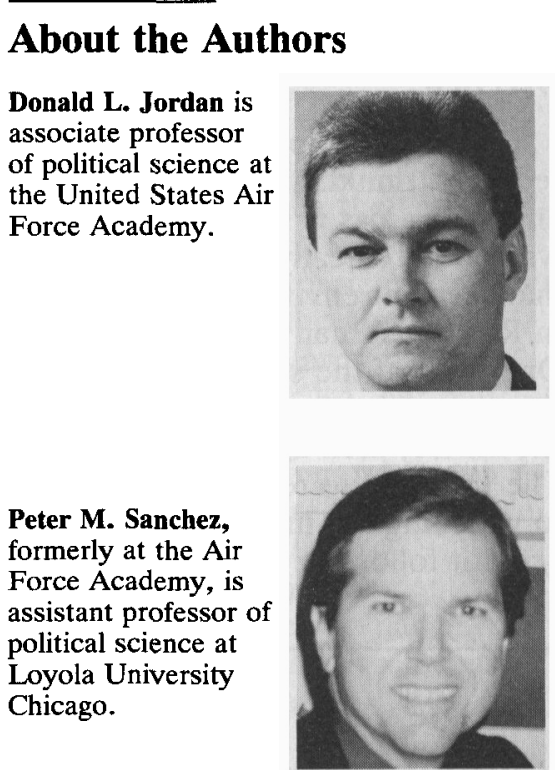

\title{
Teaching Public Administration by Exploiting Managerial Experience
}

\author{
Dorothy Olshfski, Rutgers University, Newark
}

Creating and transmitting knowledge to understand, analyze, and evaluate organizational problems is the major strength of university education in public administration. Undoubtedly, the cognitive aspects of management can be effectively transmitted in the classroom.

But understanding is one thing. Being able to perform is something entirely different (Ryles 1949). Just as swimming needs to be practiced in a pool in order to be mastered, the processes of managing need to be practiced in managerial situations, and cannot be taught through lecture alone (Mintzberg 1975).

Experience provides insight into ways a manager can accomplish tasks plus strategies for implementing ideas. In examining behavioral responses to managerial problems, Simon (1978) found that some managers have an extensive repertoire of experiences and solutions which they access more through recognition than a conscious systematic effort to recall experience. Similarly, Isenberg (1986) found that managers use analogical thinking to decide on actions to deal with organizational problems. And reasoning by analogy was described by Stone
(1988) in her model of policy analysis and by Waldrop (1992) in his description of the unfolding of the science of complexity. But in one of the few studies of what managers learn from experience, McCall, Lombardo, and Morrison (1988) found only that while different experiences provide different lessons, not all managers learned the same thing from the same situations.

But experience need not all be actual, on-the-job type of experience; it can be experience gained vicariously, i.e., secondhand. Gaining vicarious experience involves watching a person who effectively demonstrates a particular managerial behavior; analyzing the processes and behaviors used by the manager; and then attempting to model the behavior in the observer's own setting. As in most learning situations, feedback or thoughtful analysis of the effectiveness of the modeled behavior enhances the learning opportunity.

Vicarious experience can also be gained from studying history, biography, films, and analyzing managers' stories. For example, Neustadt and May (1986) advocate using historical analysis to examine the pro- cesses reportedly used by political decision makers in order to improve the decision-making skills of the observer.

Biography is also a source of vicarious experience. Doig and Hargrove (1987) and Cooper and Wright (1992) have gathered biographies of public sector leaders which can be analyzed according to the leader's strategies and behaviors. Even movies and novels, if experienced with an eye toward learning the why and how of a particular behavior, can be used to enhance managerial skills. In the classroom, the ordinary vehicle for conveying vicarious experience is the simulation or case study.

But the process of gaining and using vicarious experience to enhance mánagerial skills is an unexplored research area. This paper examines, first, the uses of experience in analyzing a management problem by practiced and novice managers. And secondly, the ease of transfer of vicarious experience is examined by presenting the participants with an experience and seeing if they can apply it to a similar case. 


\section{Methods}

\section{Overview}

Twelve participants were taperecorded thinking aloud as they analyzed a case. The case was written specifically to duplicate the management environment depicted in Robert Altman's movie, MASH. One-third of the subjects analyzed the case only. One-third watched the movie, then analyzed the case. The third group read the case prior to watching the movie, then analyzed it following the movie.

\section{... the process of} gaining and using vicarious experience to enhance managerial skills is an unexplored

\section{research area.}

MASH, directed by Robert Altman, was selected as the vehicle to provide vicarious experience. Viewed from a management perspective, MASH illustrates, among other things, strategies for surviving in a hostile organizational environment. In MASH, the army doctors are performing their tasks in an inhospitable physical work environment and coping with pressure to conform to the regular army bureaucracy. They are dedicated to performing a task competently but find the military regulations and procedures oppressive. The strategies employed by the main characters to survive are not typical strategies found in management texts: humor as a weapon, sabotage, and ignoring the chain of command. The movie was edited for research: two secondary stories were edited out of the research version because they did not address the research question of surviving in a hostile environment.

A case was written to parallel the movie (see appendix). The case attempted to duplicate the MASH situation within a state department of environmental protection. The case portrayed dedicated, but unorthodox professionals, faced with the problem of coping with pressures to conform to bureaucratic rules and procedures. The question that the students were asked to address in their analysis of the case was: What can the original managers (portrayed in the case to parallel the main characters in MASH) do to survive in their increasingly bureaucratic environment?

The think-aloud method, called verbal protocol analysis, is reported by Ericsson and Simon (1984) in their comprehensive review of the literature on the method, as usually accurate in recording cognitive processes. And it was the method used by Isenberg (1986) to study the cognitive process involved in managerial problem solving. The verbal protocol method requires subjects to verbalize their thoughts, without censoring them, as they perform an analysis of a problem. This methodology is appropriate to examining the uses of experience in managerial decision making because the subject not only articulates the final recommended strategy but also discusses strategies that were considered but rejected. If a path is not taken because of a prior bad experience, then this is important for the study of impact of experience on decision making.

All the participants in this experiment are M.P.A. students in the Rutgers program. The 12 students were divided into two groups: novices with less than five years managerial experience, and experienced managers with more than five years experience in public sector management. As it turned out, the experienced managers in the group all had more than ten years experience. (When employing verbal protocol analysis a small sample size is not uncommon. Isenberg (1986) used 15 subjects in his study. Adelson (1981) compared five expert computer programmers with five novices.)

The tapes were transcribed and examined, first, for differences in analysis between the novice and the experienced manager, and secondly, for references to the movie in the analysis. Case summaries were abstracted from the transcripts, and blind rated independently by experts for sophistication of analysis.

\section{Measures}

A synopsis of the case analysis was prepared for each verbal protocol. These synopses did not require extensive use of judgment on the part of the compiler because the interviewer had summarized the alternative discussed and the decisions made during the course of the verbal analysis and these summaries were included on the transcripts. The case synopses were presented to three members of the faculty of the Graduate Department of Public Administration at Rutgers and an executive with the New Jersey Department of Personnel who holds a doctorate in adult education. All of the raters teach or have taught management courses and make use of case studies in their classes. Each of the experts rated the case report in terms of the level of sophistication of the analysis. A four-point scale was used to rate sophistication: high, upper middle, lower middle, low. The raters were asked to place three case analyses into each category.

The complete transcripts were also coded to reflect (1) any reference to MASH, (2) any incorporation of strategies employed in the movie to the situation in the case, (3) references to personal experience, and (4) length.

\section{Results}

\section{Comparing Novices and Experienced Managers}

The protocols ranged from 170 words to 1,500 words in length, a factor of about nine. There was substantial difference between the experienced managers and the novices: the average length for the experienced managers was 1,235 words while the novices averaged 645 words. The experienced managers talked almost twice as long in analyzing the case.

References to experience differed substantially between the two 
TABLE 1

Comparison of Experienced and Inexperienced Managers

\begin{tabular}{lcccc}
\hline & $\begin{array}{l}\text { expert } \\
\text { rating }\end{array}$ & $\begin{array}{c}\text { length } \\
\text { (words) }\end{array}$ & $\begin{array}{c}\text { referenced } \\
\text { experience }\end{array}$ & $\begin{array}{c}\text { referenced } \\
\text { MASH }\end{array}$ \\
\hline Novice & $\mathrm{X}=1.875$ & $\mathrm{X}=645$ & $2 / 6$ & $3 / 4$ \\
Experienced & $\mathrm{X}=3.208$ & $\mathrm{X}=1235$ & $6 / 6$ & $4 / 4$ \\
\hline
\end{tabular}

groups of management students. Two out of six novices made reference to experience when performing the case analysis, but all six experienced managers made at least one reference to past management experiences, with the manager who received the highest score on sophistication of analysis making the most references (six) to different managerial experiences (see Table 1).

The expert ranking of the level of sophistication of the analysis performed by the participants was substantially different between the experienced managers and the novices. The scale ranged from one (lowest) to four (highest) level of sophistication of analysis. The mean rating for the experienced managers was 3.208 while the novices received a mean rating of 1.875 .

Eight subjects viewed MASH. Seven of the eight commented on the similarity between the case and the movie, but only one subject made reference to a strategy used in the movie which might be applied to the case. All of the experienced managers commented on the similarity between the two; three out of four novices saw the connection.

\section{Discussion}

To summarize the major findings of this exploratory study, experienced managers produced case analyses that were considered by experts to be substantially more sophisticated than those produced by inexperienced managers. Experienced managers talked about the management problem presented in the case almost twice as long as the inexperienced managers. Experienced managers made considerably more reference to their own experiences when analyzing the case. Al- though more experienced managers saw the connection between the case and the movie, only one manager (a novice) made the connection in terms of strategy.

All the participants in this study are students at the same place in their educational career. They share a common M.P.A. core curriculum and a pool of instructors. Experience is the item that differentiates them from each other. They analyzed the same case and movie but with very different perspectives and strategies for dealing with the problems. The novice managers were superficial and passive in their analysis of the case problem, and they tended to rely on communication as the answer.

... experienced

managers produced case analyses that were considered by experts to be substantially more sophisticated than those produced by inexperienced managers.

The experienced managers usually included some reference to communicating, but the thrust of their strategies was action. They offered detailed analysis of the situation usually drawing on their own experience to enhance their interpretation. They could easily talk at length on the situation; the novices found much less to talk about. These observations about the experienced managers support Simon (1978), Stone (1988), and Isenberg (1986) finding that managers recognized similarities between present situations and past experiences and used that comparison as a basis of analysis.

Watching a movie, even immediately before the case analysis, did not seem to influence the case analysis for either group of participants. All of the experienced managers and most of the novices mentioned the similarity between the movie and the case, but only one student considered applying a strategy used in the movie to the case situation. There may be three reasons for this.

First, it has been documented that the movies are popular during hard economic times as a means of escaping the problems of everyday life, so it may be, that for many, movie watching is a distinctly recreational activity remote from real life.

Secondly, managers may draw more readily from personal history and experience whereas learning from and using vicarious experience may require additional analysis. Managers are more likely to analyze the dynamics of personal successes and failures, which would make these experiences more relevant to future managerial decisions and behaviors. Analyzing vicarious experience would require an additional conscious effort. In this experiment no time was provided for a discussion of the movie and its managerial relevence.

And thirdly, the particular film used was chosen because the strategies used in the film were atypical and unlikely to be discussed in a formal classroom setting. It may be that the strategies were so unusual that the students needed more time and discussion before they seriously considered them as an option.

It may be that vicarious experience, like real experience, needs to be analyzed before it can be incorporated into a manager's repertoire of management strategies. Seeing alternative actions may not be enough; there may be an analysis step that needs to be included before the experience can be seriously considered by the manager.

This experiment offers some ideas for future research and teaching. First, managerial experience improves analysis, but we need to 
examine how managers learn from experience, both real and vicarious, and what types of experiences are more useful in broadening a manager's background. Secondly, we need to examine our use of simulations and case studies in the classroom. One of the important values of these teaching tools is their use in enhancing students' background of experience so they will have an expanded repertoire of experience at their disposal when working as managers. The purposes of these tools should be made explicit to the students. Finally, we need to develop a framework for analysis of vicarious experience so lifelong learning is addressed directly in our courses.

The last suggestion, developing an explicit framework for analyzing vicarious experience, is the most pressing need in management education. The literature is not informative about management education beyond the classroom and how managerial process skills are acquired and used. And considering that classroom time occupies only a small percentage of a manager's working life, identifying learning techniques and situations used by managers on the job to improve their managerial skills is an important issue that should be addressed in professional management programs.

\section{Appendix}

\section{The Strike Force and the Suits}

The office building was one of the oldest in the city; the optimist might say that the building had character. Those who characterize themselves as "realists" would say that they had seen more attractive work environments in the South Bronx. Suffice to say the building was beyond its prime and in need of paint and repair. The building housed the state's environmental protection first-line strike force. Well, that's what the professionals working there like to think of themselves as. Actually, the unit's designation was Environmental Standards Monitoring Bureau. The Bureau was established in 1981 as a response to a medical waste crisis in one of the older sections of an industrial town. Their job was to en- sure that environmental hazards that threatened public safety were discovered and removed.

The staff included six highly educated professional environmental specialists. Among the six managers were degrees in a wide range of environment-related professions: engineering, physics, chemistry, geography, and geology. The managers considered their work as important as any that the state performed, and they were widely recognized as competent and thorough. Their support staff numbered around 25 employees, skilled in providing the technological support required by the specialist/managers.

A visitor to the office might not realize at first that this was a government agency, much less one with a strong record of effective performance. There was not one person, male or female, wearing a suit. Rather, the place felt like a university student center in the early 1970s: long hair, jeans, and boots. Informality in dress was paralleled by informality in manners. The managers were indistinguishable from the staff. The office decoration scheme ranged from childishly funny to raunchy. A display entitled "The Toxic Ten" enshrined near the back entrance included some perversely funny examples of pollutants that had been encountered in the agency's nine-year history.

The group had managed to amass an impressive record of hazardous site discovery, and they were strict and fair enforcers of cleanup standards. One of the managers, a geologist who was a Trekkie, liked to say that their mission was "to seek out and discover new pollution sites and hazardous settings, to boldly go where no state environmental agency had gone before."

The industries and businesses had mixed feelings about the strike force. On one hand, they were not enamoured with the idea of spending their money to clean up their act. On the other hand, the strike force was easy to work with, nice and funny people who did not waste time with picayune details. They worked to solve the big problem and didn't sweat the small stuff.

Although the strike force really sweated it out when a new governor was elected last year and a new commissioner had been appointed to the department, nothing had come down calling for changes in the composition or modus operandi of the agency. But just when they thought that they were safe at their desks, a "suit" showed up.

"Suits," that's what they called the new members of the strike force, appointed by the new commissioner.
These new managers all dressed alike, males and females; they wore dark suits with light-colored shirts and ties. They acted as though the mission of the bureau was sacred, and they were the anointed keepers of that mission. They didn't smile much and seemed to be shocked by the jokes and displays that were common in the office. These new managers interpreted the behavior of the old guard as demonstrating a lack of concern for the mission of the bureau and their dress and interaction patterns as illustrating sloppy, unprofessional work habits. Instead of examining all the good environmental clean-up work that had been accomplished by the strike force, the suits were mainly concerned with paperwork, procedures, and bureaucratic protocol.

One particular suit was appointed to head the strike force (the suits called it the Environmental Standards Monitoring Bureau). The head suit brought in with him three other suits, and directives started to come down. First, a dress code; then a directive about office decorum and wanton displays of environmental trivia was passed around using the new memo format and buck slips. A sign-in sheet was initiated, and some of the staff people were getting docked on their paychecks for time not accounted for on the sheet. (This drove them crazy because a 50-hour week was more common than not for everyone on the staff, both managers and technicians; but now the technicians were being singled out for what they felt was ingracious treatment.)

The suits started to require that the strike force increase their documentation of all the cases on their docket; plus they initiated more paperwork to complete. The strike force was feeling swamped and angry. They couldn't get to their important work because they were being told to comply with all these bureaucratic rules.

The first personnel evaluation given to a strike force manager by the new suit cited the manager for "conduct unbecoming a state manager." This was the same guy who single-handedly convinced a large industrial polluter to clean up his act and to pay for the total cleanup to boot. Plus, the cleanup was accomplished in record time.

At first, the strike force thought that this was all a joke, and not a very funny one. But after three months, things have gone from bad to worse. The morale is in the cellar, and the work is beginning to suffer. 


\section{References}

Adelson, B. 1981. "Problem Solving and the Development of Abstract Categories in Programming Languages." Memory and Cognition, 9:422-33.

Altman, R. 1969. MASH.

Cooper, T. and D. Wright. 1992. Exemplary Public Administrators. San Francisco: Jossey Bass.

Doig, J. and E. Hargrove. 1987. Leadership and Innovation. Baltimore, Johns Hopkins.

Ericsson, K. A. and H. Simon. 1984. Protocol Analysis. Cambridge, MA: MIT Press.

Gilligan, C. 1979. In a Different Voice. Cambridge, MA: Harvard.

Isenberg, D. J. 1986. "Thinking and Managing: A Verbal Protocol Analysis of Man- agerial Problem Solving," Academy of Management Journal, 29:775-88.

McCall, M., M. Lombardo, and A. Morrison. 1988. The Lessons of Experience. Lexington, MA: Lexington.

Mintzberg, H. 1975. “The Manager's Job: Folklore and Fact," Hanvard Business Review, reprinted 1990, 90:163-76.

Neustadt, R. E. and E. R. May. 1986. Thinking in Time. NY: Free Press.

Ryles, G. 1949. The Concept of the Mind. London: Hutchinson.

Simon, H. 1978. "On How to Decide What to Do," American Economic Review, 68:1-16.

Stone, D. 1988. Policy Paradox and Political Reason. New York: Harper Collins.

Waldrop, M. Mitchell. 1992. Complexity. New York: Simon \& Schuster.

\section{About the Author}

Dorothy Olshfski teaches a seminar in leadership and a course in analytic decisionmaking techniques in the Graduate Department of Public Administration at Rutgers University in Newark. She also regularly teaches in the Certified Public Manager Program which is directed by the state of New Jersey and Rutgers University. Some of the journals in which she has published articles include the Public Administration Review, Western Political Science Quarterly, the Intemational Journal of Public Administration, and the Public Productivity and Management Review.

\title{
"Now That Was A Good Class": Learning About Politics by Observing Local Government
}

\author{
John L. Seitz, Wofford College
}

It was Friday, the day before Spring Weekend. I had just handed back their papers, which were nearly all well done. The assignment for the paper had been to attend a trial or a meeting of the city or county council. The students were to imagine that they were a member of the jury or of the council. After they described the main features of the jury trial or of a major issue the council considered, they were to indicate how they would have voted and to explain why.

Most of the class had attended a trial in the Magistrate's Court, and many of those students had waited to do this until the last possible day before the paper was due. The case many of them attended was a DUI case-driving under the influence of alcohol. The defendant was judged to be not guilty. A number of the students believed that he was guilty but had gotten off because his lawyer was better than the state trooper who was prosecuting the case.

The arrest had taken place two years before the trial. The defendant was stopped by the trooper after a traffic violation. The trooper smelled alcohol in the car, and af- ter the defendant failed two sobriety tests, which were administered on the spot, he was taken to jail where a breath analysis test was given. He scored very close to being legally drunk on that test, and was in the range where his driving ability might or might not be impaired because of his intake of alcohol.

The trooper had not taken notes during the arrest. The lawyer showed that the trooper and the policeman who administered the breath analysis test differed in their memory of where the test had been administered. The lawyer used this fact to raise doubts about the accuracy of the trooper's memory. The judge terminated the case before it went to the jury on a motion by the defendant's lawyer that insufficient evidence was presented to convict the defendant. The defendant was considered to be innocent.

Some of the students mentioned in the class that this seemed to be a situation where a "sharp" lawyer outwitted an inexperienced trooper and a guilty person was set free. "It wasn't fair," said a student.

The previous week in class we had discussed what justice means. We had learned that justice is "fair treatment under the law;' it is what is considered to be "fair" according to that society's standards. In our society, I said, we consider it "fair" that a person is considered to be innocent until proven guilty. The burden is on the state to prove, beyond a reasonable doubt, that the person charged with a crime is indeed guilty. We also consider it "fair" that it is better to let free a possibly guilty person than it is to punish a possibly innocent person. I asked the class, "Do any of you disagree with these principles?" None did, but one student then asked, “But doesn't this judgment about what is fair differ from country to country?"' I admitted that it does and stated that, indeed, it also changes within a country over time. The text had contained these ideas about justice, but now the trial which the students had attended was nicely illustrating them.

Another idea came to me during this discussion: I mentioned that our state makes the arresting police officer prosecute the case instead of using a prosecutor with legal training, thus often pitting the poor courtroom skills of a state trooper against those of an accomplished 